Available online at www.refaad.com

VMPH 2(1); 2021: 1-7

Research Article

Veterinary Medicine and Public Health Journal (VMPH)

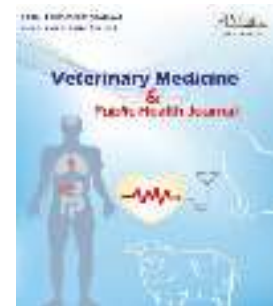

\title{
Descriptive epidemiology of Crimean - Congo hemorrhagic fever cases admitted to Kabul main hospitals during 2015 to 2018
}

\author{
Assadullah Samadi ${ }^{* a}$, Ahmad Bahram Esmatia , M. M. K. Ababneh ${ }^{b}$, M. Amiric, Mohammad Sardar Ahmadi $^{\mathrm{d}}$ \\ ${ }^{a}$ Faculty of Veterinary Science, Kabul University, Jamal Mina, Kabul, Afghanistan. \\ ${ }^{b}$ Faculty of Veterinary Medicine, Jordan University of Science and Technology, Irbid, Jordan. \\ ${ }^{c}$ Global Health Development (GHD), Amman, Jordan. \\ d Faculty of Agriculture, Logar Institute of Higher Education, Pol-e-Alam, Logar, Afghanistan.
}

* Corresponding author: Assadullah Samadi. Email: assad.samadi@gmail.com

How to cite this article: Samadi, A. et al., Descriptive epidemiology of Crimean - Congo hemorrhagic fever cases admitted to Kabul main hospitals during 2015 to 2018. Veterinary Medicine and Public Health Journal 2(1); 2021 : 1-7.

DOI: https://doi.org/10.31559/vmph2021.2.1.1 Received Date: 12/8/2020 Revised Date: 13/9/2020 Accepted Date: 27/9/2020

\begin{abstract}
Crimean - Congo hemorrhagic fever (CCHF) is a deadly viral disease which is transmitted to humans by tick bites and contact with infected animal and humans' fluids. This is a retrospective study designed to identify the descriptive epidemiology of registered CCHF cases and their related fatalities in Kabul's 12 public and private hospitals during 2015 - 2018. Totally, 521 CCHF cases and 71 deaths have been registered in two public hospitals only (mainly in Antani hospital). These cases were from 28 out of 34 provinces of Afghanistan, with more than half of the cases (50.3\%) from Kabul. More than $75 \%$ of cases were male and $24.8 \%$ were female $(\mathrm{p}<0.001)$. The median age of the CCHF patients was 29 years old (range $=3-95$ ), where majority of cases $(74.8 \%$ ) occurred in the patients between $15-45$ years old. CCHF cases have been recorded in all four seasons of the year, where the cases were $11.9 \%(61), 55.85 \%$ (291), 27.1\% (141) and 5.4\% (28) ( p <0.05) in spring, summer, autumn and winter, respectively. Results of this study indicate that CCHF is a recurrent disease in Afghanistan and the prevalence of the disease has increased dramatically in recent years. Active surveillance to detect infected and infested animals with CCHF virus and hard ticks, and combat against ticks are essential to control and prevent the disease in human populations.
\end{abstract}

Keywords: Descriptive Epidemiology; CCHF Cases; Kabul Hospitals. 


\section{Introduction}

Crimean - Congo hemorrhagic fever is an arthropod borne zoonotic viral disease with high case fatality among infected humans (Kouhpayeh 2019; Mazzola and Kelly-Cirino 2019; Moradi et al. 2019). It is caused by CCHF virus (CCHFV) which belongs to the genus Orthonairovirus, family Nairoviridae, and order Bunyavirales (Abdiyeva et al. 2019). Different species of the ticks especially Hyalomma spp. play role in the maintenance and spread of CCHFV. Once the ticks are infected, the virus persists in ticks throughout their all-life stages; but humans and animals including cattle, sheep, goat, camel, small mammals, and birds (especially ostrich) are considered amplifying hosts for CCHFV (Mostafavi et al. 2013; Chen 2013). Generally, infections are subclinical in animals and birds, but humans are the only host where clinical disease occurs (Spengler et al., 2016a, b; CFSPH, 2019).

The disease is endemic in wide range of geographic locations in the world and the viral agent is continuously expanding into new regions (Arellano et al. 2017; Spengler et al. 2016a, b). Afghanistan and its neighboring countries are considered endemic for CCHFV, and many CCHF outbreaks have been documented in recent years especially after 2013, and CCHF cases have been reported from many other countries in the region (Mustafa et al. 2011; Alam et al., 2013a, b; KeshtkarJahromi et al. 2013; Messina et al. 2015; Al-Abri et al. 2017; Moradi et al. 2019; Sahak et al. 2019; WHO, 2019; Abdiyeva et al. 2019).

Human cases of CCHF have been reported in 33 out of 34 provinces of Afghanistan, where Herat and Kabul provinces had the highest cases of CCHF, and up to date, Daykundi is the only province with no registered CCHF case (Hatami et al. 2019; Niazi et al. 2019; Sahak et al. 2019; WHO, 2019; Samadi et al. 2020). Meanwhile, seroprevalence of CCHFV in cattle and sheep in Afghanistan were estimated to be $79.1 \%$ (95\% CI 69.0\%-87.1\%) and 75.0\% (95\% CI $57.0 \%-88.5 \%$ ), respectively (Mustafa et al. 2011). These seroprevalence values are the highest in livestock in the world (Spengler et al. 2016a, b). In addition, Afghanistan is located in an endemic range of Hyalomma ticks (Hatami et al. 2019), the main reservoir and vector of CCHFV (Atif et al. 2017) which has been confirmed to be present in the county (Mustafa et al., 2011). So, tick control is the only practical approach to combat against CCHF in endemic courtiers including Afghanistan (Telmadarraiy et al. 2015).

\section{Methodology}

\section{Study design:}

The design of this study was retrospective, where the data was collected from 9 public and 3 private hospitals located in Kabul city. Data about all registered (probable and confirmed) CCHF cases from 2015 to 2018 in these hospitals were collected.

\section{Data collection methods:}

The data about CCHF cases were collected through a structured questionnaire containing questions about the number of CCHF cases, season of cases, demographic information such as age, sex, occupation and the residence of the patients (province). Meanwhile, data about the diagnostic methods, the bed duration in the hospitals and the outcome (recovered, transferred, died) of the CCHF patients in the hospitals were also collected.

\section{Data analysis:}

Data analysis was performed using Microsoft excel and SPSS software (version 20, IBM, NY, USA). Descriptive statistics including frequency tables with numbers and percentage, measures of central tendency, and measures of spread were calculated. For inferential statistics, Binomial and Chi-square tests were performed on the collected data.

\section{Results}

A total of 521 cases of CCHF including 71 deaths have been registered in Kabul's hospitals from 2015 to 2018, (no registered cases in 2014), but information regarding 26 cases that have been transferred outside the country were not available. From the 12 surveyed hospitals, only 3 cases had been registered in Indra Gandi hospital and the rest of the cases have been recorded in Antani hospital, the infectious diseases hospital in Kabul (both public), and there was no any registration about CCHF cases in the remaining surveyed hospitals. The case fatality rate (CFR) was calculated from 495 (521 - 26) cases in which the final history of patients was known and it was $14.34 \%$ (71/495). Generally, 33 cases in 2015 (22 male and 11 female), 82 cases in 2016 ( 62 male and 20 female), 192 cases in 2017 (136 male and 56 female) and 214 cases in 2018 (172 male and 42 female) have been registered in Kabul's hospitals (Figure (1). In addition, from the total recorded deaths due to CCHF (71 deaths), 5 deaths in 2015 (3 male and 2 female), 3 deaths in 2016 ( 2 male and 1 female), 20 deaths in 2017 (13 male and 7 female) and 43 deaths in 2018 (33 male and 10 female) have occurred in Kabul hospitals (Figure (2).

Based on the sex, $75.2 \%(376 / 521)$ of cases were male and $24.8 \%(119 / 521)$ were female. In addition, $72.9 \%(51 / 71)$ of death were male and $28.1 \%(20 / 71)$ were female patients (Table (1). The mean and median age of the patients were $33.48 \pm 15.9$ and 29 years old, respectively ( $\min 3$ and max 95). The Majority of CCHF cases (74.8\%) occurred in the patients between 15 - 45 years old, $14.5 \%$ of cases were in patients less than 17 years old, $49.1 \%$ in $18-35$ years old, $21.7 \%$ in $36-52$ years old and $14.7 \%$ in the patient equal or more than 53 years old $(\mathrm{p}<0.001)$ (Table $(1)$. Less than one percent $(0.8 \%)$ of cases occurred in those less than 7 years old and $1.8 \%$ of cases were in the 
people more than 70 years old Figure (3), and information regarding the age of the patients was missing for 5.8\% (30/521) of CCHF cases admitted to the hospitals during study period.

Table (1): The distribution of CCHF cases and deaths based on the sex, age groups and inpatient time in Kabul hospitals during

\begin{tabular}{|c|c|c|c|c|c|}
\hline Variable & Cases (\%) & $P$-value & Death (\%) & CFR $\%$ & $P$-value \\
\hline \multicolumn{6}{|l|}{ Sex } \\
\hline male & $376(76.0)$ & $<0.001^{\mathrm{a}}$ & $51(71.8)$ & 13.56 & $<0.001^{\mathrm{a}}$ \\
\hline female & $119(24.0 \%)$ & & $20(28.2)$ & 16.8 & \\
\hline \multicolumn{6}{|l|}{ Age categories } \\
\hline$<18$ years old & $62(14.7)$ & $<0.001^{\mathrm{b}}$ & $3(4.3)$ & 4.84 & $<0.001^{\mathrm{b}}$ \\
\hline $18-35$ years old & $203(48.1)$ & & $38(55.1)$ & 18.72 & \\
\hline $36-52$ years old & $93(22.0)$ & & $18(26.1)$ & 19.35 & \\
\hline$>52$ years old & $64(15.2)$ & & $10(14.5)$ & 15.63 & \\
\hline \multicolumn{6}{|l|}{ Inpatient time in the hospitals } \\
\hline $1-5$ days & $96(25.4)$ & $<0.001^{\mathrm{b}}$ & 47 (83.9) & 48.96 & $<0.001^{\mathrm{b}}$ \\
\hline $6-10$ days & $244(64.6)$ & & $8(14.3)$ & 3.28 & \\
\hline More than 10 days & $38(10.1)$ & & $1(1.8)$ & 2.63 & \\
\hline
\end{tabular}

${ }^{a}$ Binomial test; ${ }^{b}$ Chi - square test,

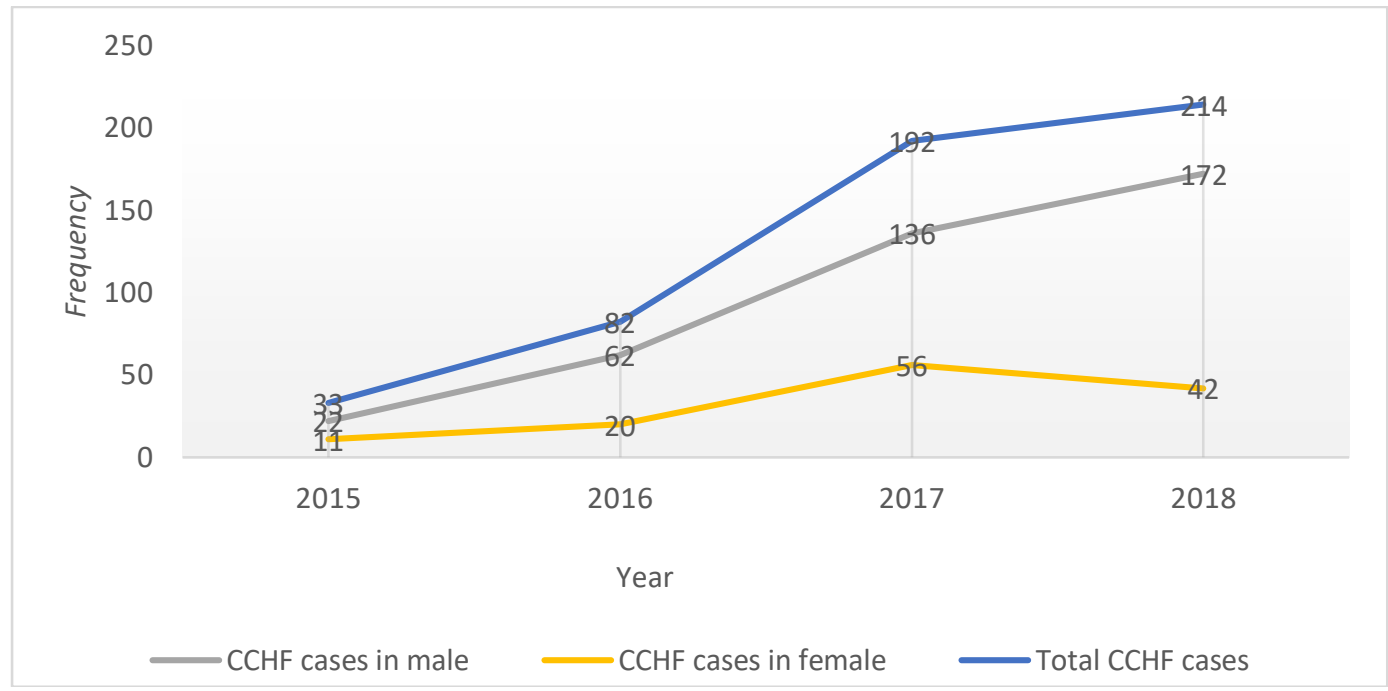

Figure (1): The trend of CCHF registered cases in Kabul hospitals during 2015 - 2018.

The mean and median inpatient time for CCHF cases in the hospital were $6.82 \pm 3.86$ and 7 days, respectively (range $=1-32$ days), but the mean and median time for patients that were released form the hospitals to be transferred overseas for better medication was $7.3 \pm 3.7$ and 7.5 days respectively (range $=1-16$ days). The inpatient time for $32.9 \%$ of the patients was 1-5 days and $58.1 \%$ of patients were kept for 6 - 10 days and only $9 \%$ of patients were kept for 11 or more days, and information regarding the inpatient time of the patients was missing for $16.7 \%(87 / 521)$ of CCHF cases hospitalized in the mentioned hospitals.

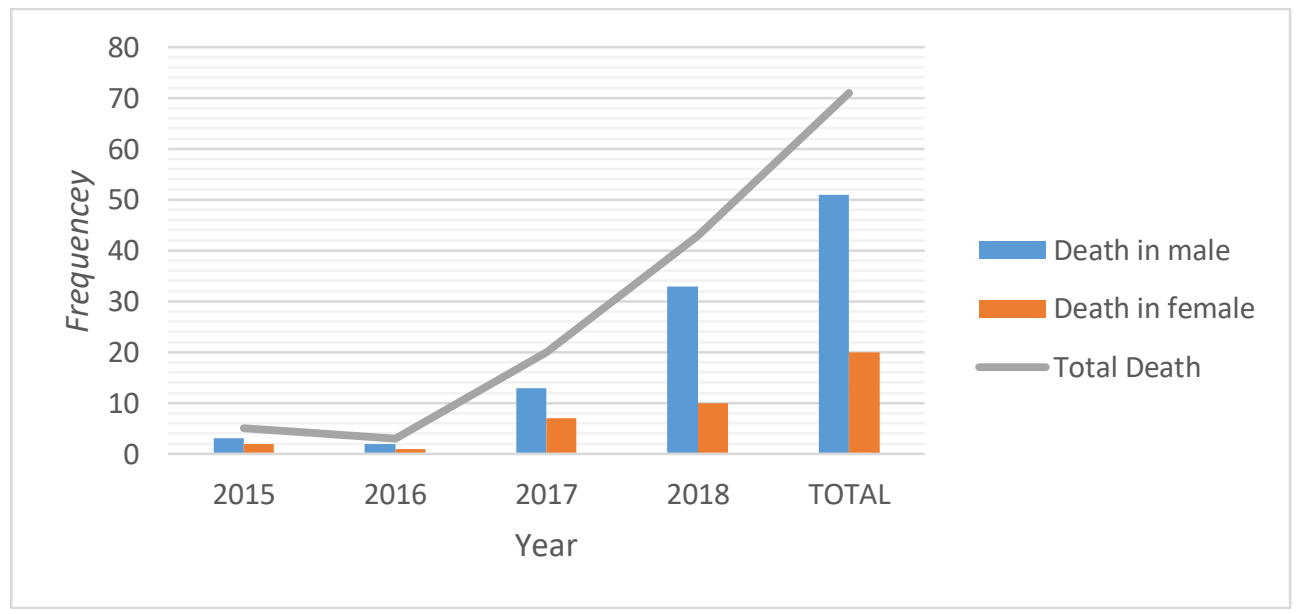

Figure (2): The trend of CCHF registered death in Kabul hospitals during 2015 - 2018 
The CCHF registered cases in Kabul's hospitals were from 28 out of 34 provinces of Afghanistan, where the highest number of cases were recorded from Kabul (262, 50.3\%), Ghazni (29, 5.6\%) and Balkh (28, 5.4\%); but less than one percent of CCHF cases has been registered from Panjshir, Kunar, Bamyan, Paktika, Kandahar, Zabul, Helmand, Nimroz, Herat and Badghis provinces; there was not any registered cases of CCHF from Uruzgan, Daikondi, Nooristan and Sar-e-Pol provinces.
Majority of cases $(61 \%, 318 / 521)$ admitted to Kabul's hospitals were from Kabul and neighboring provinces, and from central part of Afghanistan, $23.6 \%(123 / 521)$ were from north; where the least cases were from west $(0.6 \%, 3 / 521)$, east $(4 \%$, $21 / 521)$ and south $(5.8 \%, 30 / 521)$ parts of the country respectively, and the data about the residence of the patient was missing from $5 \%$ of cases (26/521).

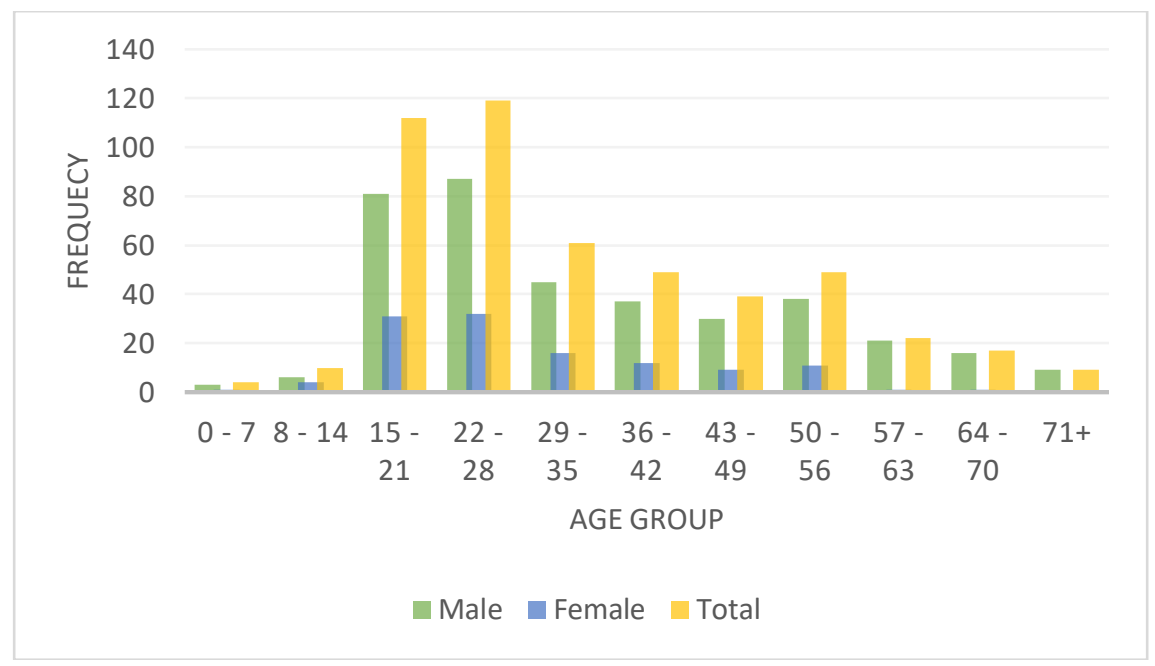

Figure (3): The number of CCHF registered cases in Kabul hospitals based on their sex in different age group during 2015 2018

The recorded data have shown that the CCHF cases occurred during all four seasons of the year, where $11.9 \%$ (61), 55.85\% (291), 27.1\% (141) and
$5.4 \%$ (28) of cases have been registered in spring, summer, autumn and winter respectively (Figure (4).

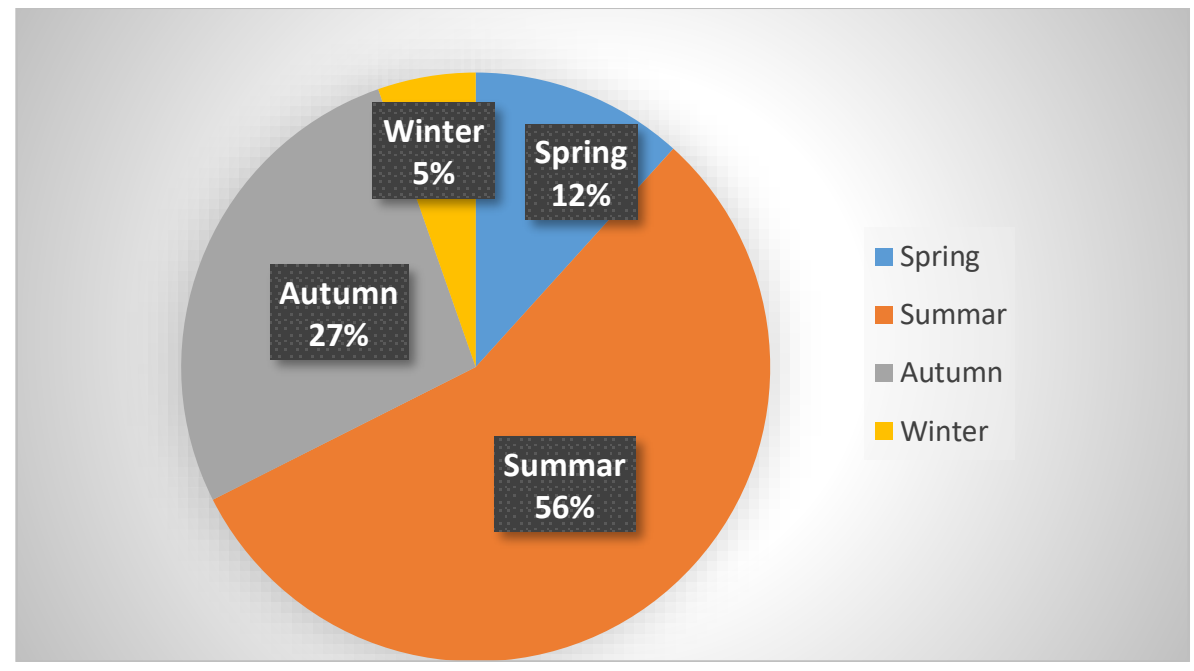

Figure (4): Distribution of CCHF cases in different seasons of the year admitted to Kabul hospitals during 2015 - 2018

\section{Discussion}

There is an endemic situation of CCHF cases in Afghanistan and neighboring countries especially Pakistan and Iran (Atkinson et al. 2012; Alam et al. 2013a, b; Chamberlain et al. 2013; Spengler et al. 2016ab, Mehran et al. 2016; FAO 2018; Sahak et al. 2019, WHO 2019), where continuous legal and illegal animal and human movements are present between the borders of these countries (Alam et al. 2013a, Moradi et al. 2019). In the present study, CCHF cases have been registered in Kabul's hospitals from 28 provinces of Afghanistan, where previous reports confirmed the cases of disease in 33 out of 34 provinces of the country (Hatami et al. 2019; Niazi et al. 2019; Sahak et al. 2019; WHO, 2019). In 
addition, most the admitted cases of CCHF in Kabul's hospitals were from the capital and central part of Afghanistan, but many other studies indicated very large number of CCHF cases especially from the west part of the country (mainly Herat province) (Mustafa 2011; WHO 2019; Sahak et al. 2019; Moradi et al. 2019). The main reason of high registered CCHF cases from Kabul and central part and the least number of cases from west, east and south parts of Afghanistan could be the referral of patients to the Antani hospital in Kabul from central parts of the country. On the other hand, the cases in west, east and south parts of the country may be admitted to provincial hospitals or transferred to the neighboring countries for medication (Pakistan and Iran). Many patients with different medical conditions, including CCHF cases, are usually transferred to Pakistan, India and sometimes to Iran (Alam et al. 2013a; Pourhossein et al. 2015). Herat province (west of the country) has had the highest number of CCHF cases in the last 10 years (Mustafa et al. 2011; WHO 2019; Hatami et al. 2019; Sahak et al. 2019; Niazi et al. 2019). In our study, we found 521 registered CCHF cases during 2015 - 2018 just in Kabul hospitals, where WHO (2019) reported $1,465$ cases and 192 deaths (CFR $=13.11 \%)$ of $\mathrm{CCHF}$ from 2013 until Aug 2019 in Afghanistan. The CFR in our study was $14.34 \%$ in Kabul hospitals, but based on many other reports (WHO 2019; Niazi et al. 2019; Kouhpayeh 2019, Mardani 2019) the average CFR of CCHF cases from 1998 until 2019 in all over the country calculated to be $30.86 \%$ (range $=11.5$ $63.2 \%$ ). Generally, the reported CFR of CCHF is considered vary in different geographical locations, and it could be $10-40 \%$ (Moradi et al. 2019).

The CCHF cases and its related fatalities have shown an increasing trend from 2015 to 2018 in Kabul's hospitals (Figure (1and Figure (2). It has been indicated that the CCHF cases have been increasing dramatically since 2013 and beyond (WHO 2018, 2019; Sahak et al. 2019; Moradi et al. 2019).

Many factors might be associated with this dramatic increment of CCHF cases in recent years in Afghanistan. Most of Afghan people raise those animals and birds (cattle, sheep, goat, camels and to a lesser degree ostriches) that are proven to be the amplifying hosts for the CCHFV and maintenance hosts for the reservoir ticks (FAO 2008; Spengler et al. 2016a, b; Champour et al. 2016; CSO, 2018, NASI, 2019). So, in Afghanistan, there are continuous exposure with animals and ticks that might be infected with the CCHFV. It has been confirmed that seroprevalence of CCHF was very high in cattle (79.1\%; 95\% CI 69.0\%-87.1\%) and sheep (75.0\%; 95\% CI 57.0\%-88.5\%) in Afghanistan (Mustafa et al. 2011), which is one of the highest recorded values in livestock (Spengler et al. 2016a, b). Most of CCHF cases $(83 \%)$ admitted to Kabul hospitals were registered in summer and autumn, the active seasons for CCHF vectors (Gargili et al. 2017). A study conducted by Mustafa et al. (2011) indicates that $84.6 \%$ of cattle and $71.5 \%$ of sheep in Herat province of Afghanistan were infested by ticks which were predominantly adult Hyalomma marginatum, the main reservoir of CCHFV (Telmadarraiy et al. 2015). In addition, drinking unpasteurized milk and eating raw meat especially liver from freshly slaughtered animals are associated with CCHFV infection (CFSPH 2019), the habits that are present in some parts of Afghanistan. Another most important risk factor that could play the key role in CCHFV exposure in Afghanistan, is the unhygienic slaughter of animals. In Afghanistan, most of the times, animals are slaughtered on the streets or at home, a practice that pose a high risk to those participating in the slaughter process. Meanwhile, there is a large movement of livestock from the rural areas to the center of cities before Eid -al - Adha (one of the Islamic feasts) in Afghanistan. During the Eid days, hundreds of thousands of animals are slaughtered, mostly at homes or on the streets. This large movement and mass slaughter of animals could play a critical role in the exposure of humans to the infected ticks and viremic animals' tissues and fluids, the two main routes where humans are infected by CCHFV (WHO 2018, 2019; CFSPH 2019). Nevertheless, the reported high number of CCHF cases in the last 7 years could be due to the increased public awareness about disease, better surveillance reporting systems, availability of sensitive diagnostic tests and so on.

Although higher proportion of males are affected, case fatality rate was reported higher for female. We found very high number of CCHF cases in male $(76 \%)$ than female $(24 \% ; p<.001)$, but CFR was high in female than male $(13.56 \%, 16.8 \%$; p $<0.001)$. Meanwhile, almost half of CCHF cases have been registered in the age category 18 - 35 years old, where the CFR was also high in the patients aged between $18-52$ years old compared to the other groups ( $\mathrm{p}<0.001)$ (Table (1). It has been proven that CCHFV infection can occur, and could be a deadly disease in any person regardless of her/his age, sex and physical status (Chinikar et al. 2012), but it has been confirmed that specific occupations like veterinarians, slaughterhouses workers, butchers, livestock handlers, farmers and health facility staffs are at high risk of CCHFV (Sharifi-Mood et al. 2014; Champour et al. 2016; Moradi et al. 2019). Previous report by Sahak et al (2019) also indicated very high number of cases in male than female (68.5\% were males and $31.5 \%$ females) in Afghanistan. In addition, they found high number of cases in the age group between $16-45$ years. The results a cross-sectional study conducted in 2009 by Mustafa et al. (2011) in Herat province of Afghanistan indicated that, daily contact with cattle $(\mathrm{p}=0.02)$ and exposure to raw animal skins $(\mathrm{p}=$ 0.006 ) were the most important risk factors for CCHF infection. In another study, the frequent reported occupational groups infected by CCHFV in Afghanistan were housewives (15\%), health staff $(13 \%)$, shepherds $(11 \%)$, butchers $(6 \%)$, students (6\%), animal dealers and farmers (both 2\%) (Sahak et al. 2019). 


\section{Conclusion}

CCHF is a recurrent disease in Afghanistan, but its cases have increased dramatically in recent years. The registered data in Kabul hospitals showed increasing trend of CCHF cases from 2015 to 2018, more cases occurred in male than female and in the age group between 15- 45 years old. The overall case fatality rate was calculated to be $14.34 \%$ where it was $13.56 \%$ and $16.8 \%$ in male and female respectively. The increasing trend of CCHF cases in recent years might be due increased exposure to infected animals or tick bites, or may be the result of increased awareness about disease or availability of diagnostic facilities. Active surveillance on animals for virus detection and tick infestation are essential, and public awareness to consider protective measures during contact with animal and infected human fluids and tissues and tick control could be the proper preventive measures against CCHF.

Study limitations: The study was designed to collect secondary data and evaluate the admitted and registered cases of CCHF in Kabul's main public and private hospitals during 2014 - 2018, but no registered cases have been found in 2014. Although there were not any registered cases in 2014, it does not mean zero occurrence of CCHF in this year. Meanwhile there were many missing data regarding the age, sex, and other related variables of the patients, which we considered important in our study. So, the differences in the number of cases, based on the mentioned variables in result section, are due to missing data. In addition, we could not find any data regarding the occupation and source of exposure of the patients infected with CCHFV.

Acknowledgement: The authors acknowledge the authorities of the Kabul public and private hospitals for providing the data on CCHF cases and related information.

Compliance with Ethical Standards: This article does not contain any studies with human participants or animals performed by any of the authors, since all of the data were secondary and collected from the registration of the Kabul hospitals.

Conflict of Interest: The authors declare that they have no conflict of interests.

\section{References}

[1] Abdiyeva K, Turebekov N, Dmitrovsky A, Tukhanova N, Shin A, Yeraliyeva L, et al. (2019). "Seroepidemiological and molecular investigations of infections with Crimean-Congo haemorrhagic fever virus in Kazakhstan", International Journal of Infectious Diseases; 78: 121-127.

[2] Al-Abri SS, Al Abaidani I, Fazlalipour M, Mostafavi E, Leblebicioglu H, Pshenichnaya N, et al. (2017). "Current status of Crimean-Congo haemorrhagic fever in the World Health Organization Eastern Mediterranean Region: issues, challenges, and future directions", International Journal of
Infectious Diseases; $58 \quad$ (2017) 82-89. https://doi.org/10.1016/j.ijid.2017.02.018.

[3] Alam MM, Khurshid A, Sharif S, Shaukat S, Rana MS, Angez M, et al. (2013). "Genetic analysis and epidemiology of Crimean Congo hemorrhagic fever viruses in Baluchistan province of Pakistan", BMC Infectious Diseases; 13(1):201. https://doi.org/10.1186/1471-2334-13-201.

[4] Alam MM, Khurshid A, Sharif S, Shaukat S, Rana MS, Angez M, et al. (2013). "Crimean-Congo Hemorrhagic Fever Asia-2 Genotype, Pakistan", Emerging Infectious Diseases; 19(6): 1017 - 1018.

[5] Arellano ER, Hernández L, Goyanes MJ, Arsuaga M, Cruz AF, Negredo A, et al. (2017). "Phylogenetic Characterization of Crimean-Congo Hemorrhagic Fever Virus, Spain", Emerging Infectious Diseases; 23(12), www.cdc.gov/eid December 2017.

[6] Atif M, Saqib A, Ikram R, Sarwar MR and Scahill S. (2017). "The reasons why Pakistan might be at high risk of Crimean Congo haemorrhagic fever epidemic; a scoping review of the literature", Virology Journal; 14(1): 63. https://doi.org/10.1186/s12985-017-0726-4.

[7] Atkinson B, Latham J, Chamberlain J, Logue C, O'Donoghue L, O'Donoghue L, Osborne J, et al. (2012). "Sequencing and phylogenetic characterization of a fatal Crimean - Congo haemorrhagic fever case imported into the United Kingdom, October 2012". Euro Surveill; 17(48): $\mathrm{pii}=20327$.

[8] CFSPH. Crimean-Congo Hemorrhagic Fever, [online] last update March 2019, retrieved from: http://www.cfsph.iastate.edu/Factsheets/pdfs/cri mean congo hemorrhagic fever.pdf

[9] Chamberlain J, Atkinson B, Logue CH, Latham J, Newman ENC, Hewson R. (2013). "Genome sequence of ex-Afghanistan Crimean-Congo hemorrhagic fever virus SCT strain, from an imported United Kingdom case in October 2012", Genome Announcements; 1(3): e00161-13. https://doi.org/10.1128/genomea.00161-13.

[10] Champour M, Chinikar S, Mohammadi G, Razmi G, Mostafavi E, Shah-Hosseini N, et al. (2016). "Crimean-Congo Hemorrhagic Fever in the OneHumped Camel (Camelus dromedarius) in East and Northeast of Iran", J Arthropod-Borne Dis.; 10(2): 168-177.

[11] Chen S. (2013). "Molecular evolution of CrimeanCongo hemorrhagic fever virus based on complete genomes", Journal of General Virology; 94(4): 843850. https://doi.org/10.1099/vir.0.049379-0.

[12] Chinikar S, Ghiasi SM, Naddaf S, Piazak N, Moradi M, Razavi MR, et al. (2012). "Serological Evaluation of Crimean-Congo Hemorrhagic Fever in Humans with High-Risk Professions Living in Enzootic Regions of Isfahan Province of Iran and Genetic Analysis of Circulating Strains", Vector-Borne and Zoonotic Diseases; 12(9): $733 \quad-738$. https://doi.org/10.1089/vbz.2011.0634 .

[13] CSO (2018). 2017-2018 Statistical years book of Afghanistan, Retrieved from: http://cso.gov.af/en/page/1500/4722/1396 
[14] FAO (2008). "Afghanistan national livestock census 2003, Food and Agriculture Organization of The United Nations", Rome, 2008, ISBN 978-92-5105950-0, retrieved from: http://www.fao.org/3/i0034e/i0034e01.pdf

[15] FAO (2018). "Afghanistan records 267 Congo cases this year, South Asia Animal Disease Outbreaks and News", Edition 13, Sep 2018, [online], retrieved from: https://menafn.com/1097345241/Afghanistanrecords-267-Congo-cases-this-year

[16] Gargili A, Estrada-Peña A, Spengler JR, Lukashev A, Nuttall PA and Bente DA. (2017). "The role of ticks in the maintenance and transmission of CrimeanCongo hemorrhagic fever virus: A review of published field and laboratory studies", Antiviral Res; 144: 93-119. https://doi.org/10.1016/j.antiviral.2017.05.010.

[17] Hatami H, Qaderi S, Omid AM. (2019). "Investigation of Crimean-Congo hemorrhagic fever in patients admitted in Antani Hospital, Kabul, Afghanistan, 2017-2018". International Journal of Preventive Medicine; 10. 117. https://doi.org/10.4103/ijpvm.IJPVM-391-18 .

[18] Keshtkar-Jahromi M, Sajadi MM, Ansari H, Mardani M, Naieni KH. (2013). "Crimean-Congo hemorrhagic fever in Iran", Antiviral Res.; 100(1): 20-28.

[19] Kouhpayeh H. (2019). "An Overview of Complications and Mortality of Crimean-Congo Hemorrhagic Fever", Int J Infect.; 6(2): e91707. https://doi.org/10.5812/iji.91707.

[20] Mardani M. (2019). "Two-Decade Experience of Crimean-Conge Hemorrhagic Fever (CCHF) Management in Iran", Arch Clin Infect Dis.; 14(4): e97887. https://doi.org/10.5812/archcid.97887.

[21] Mazzola LT, Kelly-Cirino C. (2019). "Diagnostic tests for Crimean-Congo haemorrhagic fever: a widespread tickborne disease", BMJ Glob Health; 4: e001114. https://doi.org/10.1136/bmjgh-2018-001114

[22] Mehran T, Saaid DM, Tahmineh J, Sahar K, Telmadarraiy Z, Salehi-Vaziri M. (2016). "Molecular epidemiology of Crimean-Congo hemorrhagic fever virus in ticks collected from western Iran", Asian Biomedicine; 10(6): 603 607.

[23] Messina JP, Pigott DM, Golding N, Duda KA, Brownstein JS, Weiss DJ, Hay SI. (2015). "The global distribution of Crimean-Congo hemorrhagic fever". Transactions of the Royal Society of Tropical Medicine and Hygiene; 109(8): 503-513.

[24] Moradi G, Piroozi B, Alinia C, Safari H, Nabavi M, Zeinali M, et al. (2019). "Incidence, Mortality, and Burden of Crimean Congo Hemorrhagic Fever and Its Geographical Distribution in Iran during 20092015", Iran J Public Health; 48 (1): 44-52.

[25] Mostafavi E, Chinikar S, Moradi,M, Bayat N, Meshkat M, Fard MK, Ghiasi SM. (2013). "A Case Report of Crimean Congo Hemorrhagic Fever in Ostriches in Iran". The Open Virology Journal; 7(1): 81-83. https://doi.org/10.2174/1874357901307010081.

[26] Mustafa ML, Ayazi E, Mohareb E, Sam Yingst S, Zayed A, Rossi CA, et al. (2011). "Crimean-Congo
Hemorrhagic Fever, Afghanistan", 2009, Emerging Infectious Diseases; 17(10): 1940 - 1941.

[27] Niazi A, Jawad M, Amirnajad A, Durr PA, Williams DT. (2019). "Crimean-Congo Hemorrhagic Fever, Herat Province, Afghanistan, 2017". Emerging Infectious Diseases; 25(8): 1596-1598. https://doi.org/10.3201/eid2508.181491.

[28] NSIA (2019). Afghanistan Statistical Yearbook 2018-19, Issue No. 40, July 2019, retrieved from: https://www.nsia.gov.af:8080/wpcontent/uploads/2019/11/Afghanistan-StatisticalYearbook-2018-19 compressed.pdf

[29] Pourhossein B, Doosti Irani A, Mostafavi E. (2015). "Major infectious diseases affecting the Afghan immigrant population of Iran: a systematic review and meta-analysis", Epidemiology and Health; 37 e2015002. https://doi.org/10.4178/epih/e2015002.

[30] Sahak MN, Arifi F, Saeedzai SA. (2019). "Descriptive epidemiology of Crimean-Congo Hemorrhagic Fever (CCHF) in Afghanistan: Reported cases to National Surveillance System, 2016-2018", International Journal of Infectious Diseases; 88:135-140 https://doi.org/10.1016/j.ijid.2019.08.016.

[31] Samadi A, Ababneh MMK and Amiri M. (2020). "Crimean-Congo hemorrhagic fever and its history in Afghanistan", CAB Reviews; 15(023), doi: 10.1079/PAVSNNR202015023.

[32] Sharifi-Mood B, Metanat M, Alavi-Naini R. (2014). "Prevalence of Crimean-Congo Hemorrhagic Fever among High-Risk Human Groups", International Journal of High-Risk Behaviors \& Addiction; 3(1): e11520.

[33] Spengler JR, Bergeron É, Rollin PE. (2016a). "Seroepidemiological Studies of Crimean-Congo Hemorrhagic Fever Virus in Domestic and Wild Animals". PLoS Neglected Tropical Diseases; 10(1) e0004210. https://doi.org/10.1371/journal.pntd.0004210.

[34] Spengler JR, Estrada-Peña A, Garrison AR, Schmaljohn C, Spiropoulou CF, Bergeron É, Bente DA. (2016b). "A chronological review of experimental infection studies of the role of wild animals and livestock in the maintenance and transmission of Crimean-Congo hemorrhagic fever virus", Antiviral Research; 135: 31-47. https://doi.org/10.1016/j.antiviral.2016.09.013.

[35] Telmadarraiy Z, Chinikar S, Vatandoost H, Faghihi F, Hosseini-Chegeni A. (2015). "Vectors of Crimean Congo Hemorrhagic Fever Virus in Iran", J Arthropod-Borne Dis; 9(2): 137-147.

[36] WHO (2019). "Upsurge of CCHF cases in Afghanistan", Weekly Epidemiological Monitor, 12 (33), 18 Aug 2019, ISSN 2224-4220, [online], Retrieved from: https://reliefweb.int/sites/reliefweb.int/files/resources /Epi Monitor 2019 12 33.pdf [accessed Dec 2019].

[37] WHO (2018). "Upsurge of CCHF cases in Afghanistan", Weekly Epidemiological Monitor, 11 (26), 01, July 2018, ISSN 2224-4220, [online], Retrieved

from: https://reliefweb.int/sites/reliefweb.int/files/resources /Epi_Monitor_2018_11_26.pdf [accessed Dec 2019]. 